\title{
A HOMOFOBIA FAMILIAR DISFARÇADA DE CUIDADO
}

\author{
Gilson Gomes Coelho ${ }^{(1)}{ }^{1}$ e João Henrique Oliveira Barros ${ }^{(D 2} 2$
}

\section{Resumo}

O presente estudo trata-se de uma revisão integrativa da literatura brasileira, cuja finalidade consistiu em levantar informações e reflexões acerca da homofobia vivenciada por pessoas homossexuais no seio familiar. $O$ levantamento dos dados ocorrera durante os meses de setembro e outubro de 2020, nas bases de dados: Google Acadêmico, Pepsic, biblioteca eletrônica Scielo e Banco de dados de teses e dissertações CAPES. Foram selecionados 17 estudos, dos quais foram extraídos dois eixos temáticos: A família de origem como provedora de violência; e a homofobia disfarçada de cuidado. Constatouse que apesar de haver uma quantidade relevante de discussões acerca da homofobia, ainda é escassa os estudos que envolvem a homofobia familiar. Conclui-se que os homossexuais são violentados em todos os lugares. Nota-se que é de suma importância levar as discussões a respeito do tema para além do campo acadêmico, de modo a democratizar o conhecimento e assim tentar trazer para a consciência das pessoas o quão violento são as normas sociais para pessoas homossexuais, na tentativa de romper com as práticas violentas impostas pelas normas sociais.

Palavras-chave: Homofobia Familiar; Família; Heteronormatividade; Psicologia.

\section{FAMILY HOMOPHOBIA DISGUISED IN CARE}

\section{Abstract}

The present study is an integrative review of Brazilian literature, whose purpose was to raise information and reflections about the homophobia experienced by homosexual people in the family. The survey of data had occurred during the months of September and October 2020, in the databases: Google Scholar, Pepsic, Scielo electronic library and CAPES thesis and dissertation database. 17 studies were selected, from which two thematic axes were extracted: The family of origin as a provider of violence; Homophobia disguised as care. It was found that although there is a relevant amount of discussions about homophobia,

\footnotetext{
${ }^{1}$ Doutorando em Psicologia pela Universidade Estadual Paulista "Júlio de Mesquita Filho" (UNESP/ Assis). Mestre em Psicologia pela Universidade Estadual de Maringá (UEM). Psicólogo pela Universidade Federal de Mato Grosso do Sul (UFMS/ CPAN). Docente do curso de Psicologia da Faculdade Católica Dom Orione (FACDO). E-mail: gilsonpsico@gmail.com.

${ }^{2}$ Psicólogo pela Faculdade Católica Dom Orione (FACDO). Psicólogo no Centro de Atenção Psicossocial Álcool e Drogas III no município de Araguaína, Tocantins.
}

Perspectivas em Diálogo, Naviraí, v. 08, n. 17, p. 449-463, maio/ago. 2021. 
studies involving family homophobia are still scarce. It follows that homosexuals are raped everywhere. It is noted that it is of utmost importance to take discussions on the topic beyond the academic field, in order to democratize knowledge and thus try to bring to people's awareness how violent social norms are for homosexual people, in an attempt to break with the violent practices imposed by social norms.

Keywords: Family homophobia; Family; Heteronormativity; Psychology.

\section{Introdução}

As violências multifacetadas, direcionadas a pessoas que manifestam desejo e atração sexual/ afetiva por pessoas do mesmo sexo, são chamadas de homofobia. Costa e Nardi (2015) mencionam que o termo homofobia tem sido amplamente utilizado para a conceitualização da discriminação e violência para com os sujeitos que apresentem atrações afetivas/sexuais por pessoas do mesmo sexo. Isso ocorre devido à sociedade ter sido construída dentro de um aglomerado de normas e padrões sociais, fincadas na heteronormatividade. Diante disso, os homossexuais são jogados às margens da sociedade, estando suscetíveis às inúmeras formas de violências, seja fora ou dentro de sua casa.

A família, que deveria ser um local de acolhimento e conforto, nem sempre oferta tais características, pois, ao perceber um dos seus membros se identificando como homossexual, a mesma passa a utilizar-se de comportamentos violentos, de modo a retirar o sujeito do "local de pecado" a qual se encontra, utilizando de discursos religiosos para justificar seus atos. Diante disso, é importante problematizar o que realmente significa família, uma vez que o sujeito precisa ser uma versão diferente de si para se enquadrar e ser aceito, não é uma questão de família.

Assim, considerando a importância de ampliar as discussões sobre as violências sofridas por homossexuais no ambiente familiar, este estudo tem como finalidade investigar o que tem sido discutido sobre esta temática na área acadêmica no Brasil, além de contribuir com as discussões a partir do olhar da Psicologia. Para isso, o presente estudo consiste em uma revisão integrativa da literatura, construída por intermédio de estudos que fomentaram discussões sobre a homofobia familiar e questões que atravessam este tema.

Por meio desta revisão, propõe-se construir informações e reflexões a respeito da temática, na tentativa de barrar ou amenizar as violências sofridas pelos homossexuais na sociedade contemporânea, além de somar as discussões e pesquisas acerca da temática, especialmente no campo da Psicologia, sobretudo por se tratar de um campo do saber que se preocupa em promoção da saúde e do bem-estar das pessoas e das coletividades, contribuindo para a destruição de quaisquer configurações de negligência, discriminação, exploração, violência, crueldade e opressão (CONSELHO FEDERAL DE PSICOLOGIA, 2005). 


\section{A Família e a homofobia}

A família é uma construção social que liga as pessoas por laços sanguíneos e laços de afeto, uma instituição responsável pelo cuidado e proteção de seus membros, sendo um ambiente acolhedor e fraterno. De acordo com Dessen e Braz (2005) a família é de fundamental importância para a socialização dos sujeitos, é a partir dela que os seus membros irão construir suas primeiras relações sociais e parte da sua identidade, que por sua vez é um processo em constante transformação, sendo multideterminado por fatores do próprio indivíduo e por aspectos mais amplos do contexto social no qual estão inseridos.

Essa concepção de família mencionada anteriormente foi construída socialmente a partir de um prisma heteronormativo, que diz respeito a uma cultura que impõe normas, valores, princípios de condutas e dispositivos, apoiada em uma perspectiva que julga a heterossexualidade como a única possibilidade legítima e natural de expressão identitária e sexual. É construída por leis sociais, que controlam o desejo e a projeção dos gêneros e que, para esse fim, precisa ser continuamente repetida e reiterada, a fim de provocar um efeito natural, sem muitos questionamentos e problematizações (WARNER, 1993).

Em harmonia com Foucault (2005) a sociedade é moldada a partir da disciplinarização dos corpos, isto é, as instituições de poder utilizam-se de seus princípios para criar uma população conforme suas normas. Para isso, usam como referência o homem branco, heterossexual, urbano, de classe média e cristão. Tudo que vai em desencontro com tais características são vistos como "anormais", estando suscetível a qualquer tipo de violência. É através dessa classificação, que se firmam as normas e padrões sociais, onde, mediante as contribuições do cristianismo, da heteronormatividade e do patriarcado, financiado pelo capitalismo, aponta-se o que pode ser vivido ou visto no ambiente público e no privado, sendo um processo violento para quem não se enquadra. Butler (2019) relata que os corpos que não seguem o perfil heteronormativo passam a ser corpos sem valor social, que é o caso dos homossexuais, que são sujeitos que se relacionam afetivo/sexual com pessoas do mesmo sexo.

Todavia, apesar do processo violento vivenciado pelo sujeito homossexual por não se enquadrar nas normas sociais, observa-se que por muito tempo não houve discussões sobre tais ações, pois, além da naturalização da heterossexualidade, a sexualidade, ou o sexo, como era dito, era visto como algo desvinculado do social, dado que viver a sexualidade era algo exclusivamente da vida adulta que era experienciado no modo privado com um companheiro do sexo oposto (LOURO, 2020). Entretanto, Foucault (2005) expõe que a sexualidade é um "dispositivo histórico", devido ter sido criada e estabelecida a partir do social, mediante inúmeros discursos sobre o sexo, discursos estes que visavam a dominação dos corpos a partir de regulações que normatizavam, instauravam saberes e produziam verdades. 
Conforme Kruczeveski e Mariano (2014) a moral cristã, em especial a propagada pela Igreja Católica, foi e ainda é, uma das principais colaboradoras para a formação de um modelo de família baseado na heteronormatividade, colocando como exemplo de justificativa a imagem da sagrada família. Além do mais, verifica-se que no modelo de família em discussão, há uma estrutura baseada no patriarcado, isto é, existe uma organização hierarquizada que coloca a figura do homem acima dos demais membros. O sistema patriarcal segundo Narvaz e Koller (2006) concerne em um modo de estrutura social marcada por dois princípios básicos que são: a mulher hierarquicamente inferior à figura masculina e, segundo, os homens mais novos hierarquicamente inferiores aos homens mais velhos, um sistema que assegura regalias aos homens, somente por dispor de um pênis.

Butler (2003) expõe que essa organização social que se estabelece baseada nas genitálias, refere-se às discussões tocantes ao gênero. A autora relata que o gênero é uma construção cultural infindável, um ato performativo inconstante e contextual. É entendido para além da simples representação de funções a serem executadas por corpos de homens e mulheres frente ao domínio da heteronormatividade, é uma complexidade infindavelmente aberta. Dessa forma, entende-se que o gênero é uma representação que é experienciada pelas performances dos indivíduos sociais que as vivenciam por intermédio da vivência espacial cotidiana e concreta.

Ao buscar compreender a ligação entre patriarcado e família, observa-se que é algo que caminha com a humanidade, uma vez que o termo "família" é proveniente do latim, que significa "escravo doméstico". Se firmou como instituição na Roma Antiga. A família romana se organizava a partir da valorização da figura masculina, colocando as mulheres como subalternas dos homens. O patriarca de cada família gozava de muitos poderes para com sua esposa, seus filhos e seus escravos, dentre eles o de vida e morte de cada um (ENGELS, 2009); (XAVIER, 1988).

Contudo, é importante ressaltar que o patriarcado não concede o poder ao pai, e sim aos homens. Além disso, essa cultura está sempre em constante transformação, se atualizando de acordo com a época e a cultura de cada local, ganhando aspectos mais modernos. Na atualidade, lamentamos a observação rotineira de contornos patriarcais transvestidos de heteronormatividade $\mathrm{e}$ misoginia. Os princípios que alçam a heteronormatividade e a misoginia se mantém apoiado em pressupostos patriarcais. Assim, constata-se que a instituição familiar, apesar de muitas discussões e problematizações, ainda é tida como uma ferramenta que atua na conservação do patriarcado (BORGES; PERURENA; PASSAMANI; BULSING, 2013).

Diante das discussões já mencionadas no decorrer deste estudo, observase que os homossexuais, são vistos como um parafuso solto na engrenagem da sociedade e que, devido a isso, são violentados de inúmeras formas, como uma forma de punição por transgredir as normas. Santos (2002) relata que os homossexuais têm o poder de ameaçar o sistema, pois, coloca em contradição tudo aquilo que foi ensinado a partir da religião, onde o homem nasce, cresce e 
constrói família, além de inúmeras regras criadas pelo patriarcado e demais culturas violentas.

Por serem vistos como ameaça ao sistema, os homossexuais são violentados cotidianamente e, na tentativa de se proteger, muitos homossexuais se veem na necessidade de esconder os seus desejos em um local privado. Esse local responsável por guardar os desejos "proibidos" é chamado de "armário". Sedgwick (2007) explica que o "armário" concerne em um dispositivo de poder presente desde meados do século XIX, que atua como um reforçador do dualismo hétero-homo. Oliveira (2019) explica que o "armário" para as pessoas não-heterossexuais é visto como sinônimo de proteção, um lugar que o sujeito pode ser o que ele realmente é e quer ser.

\section{Metodologia}

O presente estudo concerne em uma revisão integrativa da literatura brasileira a respeito da homofobia no seio familiar, a qual objetivou-se produzir conhecimento de cunho informativo e reflexivo. A revisão integrativa, segundo Souza, Silva e Carvalho (2010), se trata de um método que propõe compilar informações e sintetizar os resultados da pesquisa a respeito de um determinado assunto, sendo um método muito importante dentro do campo científico, uma vez que promove a democratização do acesso, além de propiciar a atualização frequente do tema.

Inicialmente foram definidos os critérios de inclusão, sendo eles: (a) materiais científicos que elencaram embasamentos relevantes no desenvolvimento da temática na área acadêmica; (b) estudos nacionais, por se tratar de uma pesquisa cultural, que pode haver diferenciação dependendo de cada localidade; (c) estudos publicados até a data da busca. Como critérios de exclusão, foram descartados os estudos que não traziam discussões fundamentadas e bem desenvolvidas sobre a temática em análise e estudos internacionais. Logo em seguida foi realizada a busca dos materiais.

A busca ocorreu durante os meses de agosto a setembro de 2020, nas seguintes bases de dados: Google Acadêmico, Pepsic, biblioteca eletrônica Scielo e Banco de dados de teses e dissertações CAPES. Onde se utilizou dos descritores: homofobia familiar, homossexualidade e família, violência e heteronormatividade. Após a busca dos estudos, foram selecionados 17 estudos para compor a amostra. Posteriormente foram analisadas as amostras, utilizando-se de uma tabela para melhor organizar as informações, em seguida iniciou-se a interpretação dos resultados e a apresentação da revisão integrativa.

\section{Resultados e discussões}

Por meio da aplicação dos descritores nas bases de dados selecionadas para a pesquisa, o processo de busca dentro dos critérios de inclusão e exclusão estabelecidos, obteve como resultado 17 estudos, sendo artigos, livros e 
dissertações que elencaram reflexões e discussões importantes para a desnaturalização da heterossexualidade e reflexões acerca da violência sofrida em um ambiente que deveria ser de acolhimento e companheirismo, que é a família.

Observou-se que as amostras selecionadas são em sua maioria, do campo das ciências sociais, destacando o campo da Psicologia como um dos principais campos de pesquisa que se esforçou para discutir e elencar reflexões acerca da temática em questão. Além disso, notou-se também que apesar das violências contra homossexuais se tratar de algo que acompanha a humanidade, ainda não há muitas discussões a respeito do tema, dado que as publicações selecionadas, em sua maioria, foram introduzidas no campo científico recentemente, no período de 2008 a 2020.

Para melhor organização e identificação das amostras, criou-se o quadro a seguir. $\mathrm{O}$ quadro é formado pelos nomes dos autores, ano de publicação e título do estudo. Logo em seguida inicia-se a discussão dos resultados, que foram organizados em dois eixos temáticos, sendo eles: A família de origem como provedora de violência; A homofobia disfarçada de cuidado.

\section{Quadro 1: Tabela referente aos estudos analisados}

\begin{tabular}{lcl}
\hline AUTORES & ANO & \multicolumn{1}{c}{ TítULO } \\
\hline BORRILLO, D. & 2010 & $\begin{array}{l}\text { Homofobia: história e crítica de um } \\
\text { preconceito }\end{array}$
\end{tabular}

BRAGA, I. F.; OLIVEIRA, W. A.; SILVA, J. L.; MELLO, M. A. I; SILVA, M. A. I.

BRITO, T. H. S.

CANCISSU, C. R. P.

DONZELOT, J.

FEITOSA, C.

NASCIMENTO, G. C. M.; SCORSOLINI-COMIN.

PERUCCHI, J.; BRANDÃO, B. C.; VIEIRA, H. I. S.
2018 Violência familiar contra adolescentes e jovens gays e lésbicas: um estudo qualitativo

2019 Uma análise sobre as formas de violência familiar contra pessoas LGBTQI+.

2007 Lésbicas, família de origem e família escolhida: um estudo de caso

1986 A polícia das famílias

2016 As diversas faces da homofobia: diagnóstico dos desafios da promoção de direitos humanos LGBT

2018 A Revelação da Homossexualidade na Família: Revisão Integrativa da Literatura Científica

2014 Aspectos psicossociais da homofobia intrafamiliar e saúde de jovens lésbicas e gays 
PRADOS, N. C. C.; BRANDÃO, B. C.;

PERUCCHI, J.

RAMOS, D. O.

SANTOS, M. A.

BROCHADO JUNIOR, J. U.;

MOSCHETA, M. S.

SANTOS, M. R. N.;

GODOY, E. A.

SCHULMAN, S.

SILVA, S. G.; FRANÇA, A. $\mathrm{N}$

SOLIVA, T. B.; SILVA

JUNIOR, J. B. D.

TOKUDA, A. M. P.; PERES, W. S.; ANDRÊO, C.

TOLEDO, L. G.; TEIXEIRAFILHO, F. S.
2016

2007 Grupo de pais de jovens homossexuais

2010

Homofobia familiar: uma experiência em busca de reconhecimento.

Por onde circulam os corpos invisíveis?

Intersecções entre população em situação

de rua e gêneros dissidentes no acesso

institucional urbano

Famílias e homossexualidade: a experiência

no centro de cidadania LGBT da capital.

2019 Família e escola: a construção da homofobia no Brasil.

2019

Vidas Precárias: a Performatividade na

Constituição das Violências Fóbicas em

Gêneros e Sexualidades.

2014 Entre revelar e esconder: pais e filhos em

face da descoberta da homossexualidade

2016 Família, gênero e emancipação psicossocial

2013 Homofobia familiar: abrindo o armário entre quatro paredes

Fonte: Elaborada pelos autores (2021).

\subsection{A família de origem como provedora de violência}

A família de origem é entendida como um grupo de pessoas ligadas por laços sanguíneos e laços de afetos, sendo constituída por um casal heterossexual e seus filhos. Sua estrutura está relacionada com o cenário histórico vivenciado pela sociedade ao longo da sua construção, e isto irá variar por meio da conjuntura social, cultural, política, econômica, etc. Embora já tenha acontecido inúmeras mudanças na sociedade, ainda é possível observar diversas formas de resistência relacionada à aceitação de uma pessoa homossexual no contexto familiar, por ainda haver um modelo hegemônico familiar, patriarcal burguês (RAMOS, 2016).

Em harmonia com Perucchi, Brandão e Vieira (2014) essa instituição é considerada como uma criação social moldada a partir das amarras das (1)(1) 
instituições de poder, onde atua como um dispositivo regulador da norma. Entretanto, devido a sua naturalização, acaba passando despercebido todas as violências localizadas dentro do seu contexto. Observa-se que a sociedade agrega inúmeras características positivas acerca da família de origem, dentre elas encontram-se a afetividade, o companheirismo, a segurança e o acolhimento. Contudo, sabe-se que tais características só são demonstradas para membros que seguem o modelo heteronormativo. Assim, a família de origem ao perceber um dos seus membros se reconhecendo como homossexual, acaba por tentar aniquilar todas as formas de subjetividade daquele membro, na tentativa de silenciá-lo.

Essa administração da sexualidade realizada pela família de origem é uma ação financiada pelo Estado. Segundo Donzelot (1986) o Estado atribui a família o papel de vigilante, aonde irá se preocupar em manter seus membros de acordo com as normas sociais vigentes, de preferência sem muitos questionamentos, construindo sujeitos dóceis e facilmente manipuláveis. Quando o sujeito não se enquadra nas normas sociais vigentes, acaba sendo desmembrado dos laços familiares, o autor menciona que o não pertencimento a uma instituição familiar coloca os sujeitos como uma objeção de ordem pública, julgando-os como vagabundos que, por não estarem em nada ligados ao aparelho social, executam o ofício de perturbadores do sistema, contribuindo com as ações de biopoder, que se trata de um método que se esforça para formar sujeitos politicamente dóceis. Para isso, disciplinam os corpos e as biopolíticas reguladoras das vivências interpessoais e familiares (TOKUDA; PERES; ANDRÊO, 2016).

Por estar localizada dentro de uma sociedade heteronormativa, a família de origem é encarregada por construir que trilhem passos da heterossexualidade e propaguem os princípios advindos da mesma, tendo como principal exigência a reiteração contínua da sexualidade "aceita", com o propósito de transformar esse fenômeno o mais natural possível (PERUCCHI; BRANDÃO; VIEIRA, 2014). Entretanto, sabe-se que a família de origem, nem sempre consegue "educar" seus membros para ser heterossexual. Devido a isso, inicia-se várias formas de violência para com o homossexual, em nome do "amor e proteção", resultado da promoção de preceitos promovidos pelo cristianismo, que por muito tempo fez uso de narrativas homofóbicas em nome da fé e da moral, narrativas estas que refletem até os dias de hoje (BRITO, 2019). Esse processo de moralização é responsável pela produção da exclusão social, com propensa a inferiorizar e demonizar os homossexuais e seus relacionamentos (SANTOS; GODOY, 2019).

$\mathrm{Na}$ tentativa de se proteger, o sujeito decide continuar dentro "armário", por ser um lugar seguro para manter seus desejos, retirando do ambiente público tudo aquilo que contradiz com a heterossexualidade, sendo mais uma forma de violência vivencia pelo homossexual, dado que o sujeito precisará se esforçar para construir uma sexualidade falsa e insuspeita, que por diversas vezes é colocada à prova pela sociedade, o que fazem com que muitos homossexuais tenham comportamentos violentos para com outros homossexuais. Para Nascimento e Scorsolini-Comin (2018) a saída de casa é uma das formas viáveis, onde o sujeito se agrega a um grupo de amigos, que 
geralmente saíram de casa devido às mesmas circunstâncias, formando assim, um grupo de apoio.

Segundo Cancissu (2007) os amigos passam as ser uma nova família, oferecendo um ambiente respeitoso e acolhedor para os diferentes desejos e gostos de cada membro, geralmente pouco encontrado em uma sociedade heteronormativa, operando como facilitadora na construção e aceitação da identidade homossexual, oferecendo referências de identificação importantes para a edificação da identidade, proporcionando exteriorizar os desejos fora das limitações impostas pela família de origem.

É importante mencionar que nem sempre os sujeitos homossexuais conseguem encontrar um grupo de apoio e que devido a isso buscam outras alternativas para fugirem das violências familiares, dentro dessas alternativas, encontra-se a rua e o suicídio. Dessa forma, é de suma importância refletir sobre o que realmente é família, na tentativa de desnaturalizar e retirar esse olhar romantizado de instituições provedoras de violência. Deve-se pensar em uma organização familiar ligada a intimidade, trocas e respeito, pois, quando o sujeito precisa performar uma versão diferente de si para se integrar e ser aceito, não é uma questão de família (FEITOSA, 2016); (BRAGA; OLIVEIRA; SILVA; MELLO; SILVA, 2018).

\subsection{A homofobia disfarçada de cuidado}

A homofobia refere-se a uma ação de hostilidade em contraposição aos homossexuais, um sentimento de fobia, repulsa e ódio que leva a abjeção, a desumanização, a distinção e o afastamento do indivíduo homossexual (BORRILO, 2010). A homofobia atua através de crimes, patologizações, violências físicas e psicológicas e demonizações, regularmente acarretando o extermínio de pessoas não-heterossexuais no mundo contemporâneo, sem que as pessoas que comentem esses atos sejam punidas (SILVA; FRANÇA, 2019). $\mathrm{Na}$ visão de Perucchi, Brandão e Vieira (2014) a homofobia se aproxima de outros modos de discriminação, como o racismo e a xenofobia, uma vez que se baseia no julgamento do outro, no caso o homossexual, apontando-o como anormal e inferior, configurando-se como um meio utilizado para criar e exibir um sistema de desigualdades que reforçam a exclusão e a dominação de uns sobre outros.

Santos, Brochado Júnior e Moscheta (2007) expõe que a família de origem, situada dentro de um sistema que apresenta narrativas a respeito da repulsa pelo homossexual, se esforça para retirar do meio social aquilo que vai contra as diretrizes das normas. Desse modo, ao notar que um dos seus membros estão se comportando de forma irregular, isto é, se percebendo como homossexual, a família de origem passa a ver o filho como alguém doente ou louco, buscando incessantemente entender os motivos que levaram o filho a "escolher" ser homossexual.

Ao não encontrar nenhuma resposta, inicia-se às tentativas de tirar o filho da homossexualidade, para isso, utilizam de várias formas de violências. 
Isso ocorre porque a família de origem também se sente coagida moralmente por uma sociedade que normatiza e estabelece o que são os papéis de gênero. $\mathrm{E}$ quando não se conseguem enquadrar homens e mulheres em seus papéis preestabelecidos socialmente, muitos dos pais se sentem fracassados em sua missão, passando a praticar diversos tipos de abuso e violência contra seus filhos (RAMOS, 2016).

Essas violências para com os homossexuais citadas anteriormente são expressadas de diversas formas, podendo ser agressões, ameaças e outras tantas variações, que serve para deixar evidente a tamanha intolerância que a família de origem demonstra no momento em que se esbarra com a presença de um transgressor das normas (SOLIVA; SILVA JUNIOR, 2014). Essa violência existente no seio da família de origem para com o sujeito homossexual, denomina-se como homofobia familiar. Toledo e Teixeira-Filho (2013) explicam que a homofobia familiar diz respeito a um fenômeno que está presente na vida dos homossexuais e, que se define como uma extensa crise cultural, uma vez que se trata de uma violência inequívoca, mas que é invisibilizada por ter o apoio das instituições de poder, onde justificam-na a partir de um discurso de reparação, capaz de trazer a pessoa a "normalidade", isto é, de volta a heterossexualidade (BRITO, 2019).

Schulman (2010) relata que as particularidades e dimensão da homofobia familiar são amplas, iniciando com pequenos desrespeitos até chegar em violências mais brutais e cruéis, que acabam de fato com a vida do sujeito. Em suma, a homofobia familiar é um modo de preconceito que se localiza dentro do contexto familiar como mecanismo de validação da violência, que acaba motivando o corte das relações familiares. O lar torna-se um local de contradições, uma vez que se espera que ele seja um lugar minimamente respeitoso (NASCIMENTO; SCORSOLINI-COMIN, 2018);

Segundo Braga, Oliveira, Silva, Mello e Silva (2018) o sujeito por não se ver pertencente à família de origem, passa a buscar formas de se livrar do sofrimento e da violência. Dessa forma, observa-se que uma parte das pessoas homossexuais conseguem sair de casa sem muitas implicações, pois, dependendo das condições financeiras e sociais, o mesmo consegue o apoio de grupos de amigos, que passam a ser sua nova família, ou até mesmo, adquire um lugar próprio, em outros termos, comprar ou alugar algum imóvel. Contudo, uma parte dessas pessoas não desfrutam desse privilégio e veem na rua a forma mais rápida para se livrar da violência familiar, se colocando em um ambiente ainda mais violento.

Diante das discussões já expostas, nota-se que a família de origem que deveria atuar como parte fundamental no cuidado e proteção dos seus membros, acaba sendo uma peça na engrenagem dos dispositivos de poder, colaborando para a estimulação de situações violentas e constrangedoras para com os homossexuais que procuraram refúgio em suas redes de apoio ou na rua. Assim, segundo Perucchi, Brandão e Vieira (2014) o contexto familiar de origem, que deveria ser um local de respeito, segurança e companheirismo passa a ser um ambiente violento, que busca normatizar o sujeito, através de dispositivos 
hostis, a modelos binários e naturalizados de exercício da sexualidade. Concorda-se com Prados, Brandão e Perucchi (2018) onde mencionam que na contemporaneidade "não se manda mais matar, simplesmente deixa-se morrer" com base de todas as discussões elencadas neste estudo, que colocam os homossexuais em situações de violência, seja ela sexual, psicológica ou física.

\section{Considerações finais}

Buscou-se apresentar neste artigo, discussões a respeito da homofobia vivenciada no seio familiar, adotando uma postura informativa e reflexiva. Diante das discussões realizadas neste trabalho, ressalta-se a importância de mais discussões envolvendo a temática, principalmente por se tratar de um fenômeno que há muito tempo violenta os sujeitos que trilham passos nãoheterossexuais. Pelos achados encontrados, fica clara a necessidade de elaboração de investigações que busquem expor assuntos relacionados com a temática na literatura científica brasileira, uma vez que não foi encontrado uma quantidade expressiva de estudos sobre o assunto e, os encontrados são, em sua maioria, discussões relacionadas com a homofobia, não sendo propriamente a homofobia familiar.

Notou-se durante as buscas que apesar de toda a controvérsia que cerca o termo homofobia, esse foi o descritor que mais apresentou estudos nas bases de dados selecionadas. Desse modo, é importante que haja cada vez mais estudos, trazendo discussões importantes acerca de outros assuntos que perpassam a homofobia, a fim de que o vocabulário se amplie e outros termos ganhem visibilidade na literatura brasileira. Além disso, é de suma importância levar essas discussões para além do campo acadêmico, de modo a democratizar o conhecimento e assim tentar trazer para a consciência das pessoas o quão violento são as normas sociais para pessoas homossexuais, na tentativa de romper com as práticas violentas impostas pelas normas sociais.

No campo da Psicologia, é fundamental pensar em novas discussões a respeito da temática, sobretudo por ser uma área do saber que se atenta em eliminar as formas de violência e opressão dentro da sociedade, fazendo cumprir o que é exposto em seu código de ética. Além disso, é importante que esse campo use seus fundamentos para informar, de forma apropriada, as famílias, favorecendo-as na mudança de consciência e positivação da autoestima de seus integrantes, dado que essa instituição tem muita influência na produção de subjetividade de seus membros.

\section{REFERÊNCIAS}

BORGES, Zulmira Newlands; PERURENA, Fátima Cristina Vieira; PASSAMANI, Guilherme Rodrigues; BULSING, Muriel Bulsing. Patriarcado, heteronormatividade e misoginia em debate: pontos e contrapontos para o combate à homofobia nas escolas. Latitude, v. 7, n. 1, 2013. Disponível em: 
https://www.seer.ufal.br/index.php/latitude/article/view/1065/0. Acesso em: 09 set. 2020.

BORRILLO, Daniel. Homofobia: história e crítica de um preconceito. Belo Horizonte: Autentica Editora, 2010.

BRAGA, Iara Falleiros; OLIVEIRA, Wanderlei Abadio de; SILVA, Jorge Luiz da.; MELLO, Flávia Carvalho Malta de.; SILVA, Marta Angélica Iossi. Violência familiar contra adolescentes e jovens gays e lésbicas: um estudo qualitativo. Revista Brasileira de Enfermagem, v. 71, p. 1295-1303, 2018. Disponível em: https://www.scielo.br/scielo.php?pid=S0034-

71672018000901220\&script=sci_arttext\&tlng=pt. Acesso em: 02 set. 2020.

BRITO, Thais Hesper Silva. Uma análise sobre as formas de violência familiar contra pessoas LGBTQI+. (Trabalho de Conclusão de Curso). Universidade Católica do Salvador, BA, Brasil, 2019.

BUTLER, Judith. Problemas de gênero: feminismo e subversão da identidade. Rio de Janeiro: Civilização Brasileira. 2003.

BUTLER, Judith. Corpos que importam: os limites discursivos do "sexo". São Paulo: n-1 edições, 2019.

CANCISSU, Cynthia Regina Pemberton. Lésbicas, família de origem e família escolhida: um estudo de caso. Dissertação (Mestrado em Psicologia Clínica), Pontifícia Universidade Católica de São Paulo, SP, Brasil, 2007.

CONSElHo federal de PSicologia. Código de Ética Profissional do Psicólogo. Brasília, 2005.

COSTA, Ângelo Brandelli; NARDI, Henrique Caetano. Homofobia e Preconceito contra Diversidade Sexual: Debate Conceitual. Temas em Psicologia, v. 23, n. 3, p. 715-726, 2015. Disponível em: http://pepsic.bvsalud.org/scielo.php?script=sci_arttext\&pid=S1413389X2015000300015. Acesso em: 20 dez. 2020.

DESSEN, Maria Auxiliadora; BRAZ, Marcela Pereira. A família e suas interrelações com o desenvolvimento humano. In: DESSEN, Maria Auxiliadora; COSTA Jr., Anderson Luiz (Org.). A ciência do desenvolvimento humano: tendências atuais e perspectivas futuras. Porto Alegre: Artmed, 2005, p.113-131.

DONZELOT, Jacques. A polícia das famílias. 2. ed. Rio de Janeiro: Graal, 1986.

ENGELS, Friedrich. A origem da família, da propriedade privada e do Estado. Clube de Autores, 2009. 
FEITOSA, Cleyton. As diversas faces da homofobia: diagnóstico dos desafios da promoção de direitos humanos LGBT. Periódicus, n. 5, p. 300-320, 2016. Disponível em:

https://portalseer.ufba.br/index.php/revistaperiodicus/article/view/17193. Acesso em: 26 out. 2020

FOUCAULT, Michel. História da Sexualidade, v. I: a vontade de saber. São Paulo: Graal, 2005.

KRUCZEVESKI, Lais Regina; MARIANO, Silvana Aparecida. Família nuclear patriarcal: breves notas sobre a (re) construção da teoria social e os estudos feministas. Anais da UEL, UEL, Londrina, p. 1-8, 2014. publicas.php. Acesso em: 22 set. 2020

LOURO, Guacira Lopes. Um corpo estranho: ensaios sobre sexualidade e teoria queer. 3. ed. Belo Horizonte: Autêntica, 2020.

NARVAZ, Martha Giudice; KOLLER, Sílvia Helena. Famílias e patriarcado: da prescrição normativa à subversão criativa. Psicologia \& Sociedade, v. $18, \mathrm{n}$. 1, p. 49-55, 2006. Disponível em:

https://www.scielo.br/scielo.php?pid=S0102-

71822006000100007\&script=sci_abstract\&tlng=pt. Acesso em: 19 set. 2020.

NASCIMENTO, Geysa Cristina Marcelino; SCORSOLINI-COMIN, Fábio. A Revelação da Homossexualidade na Família: Revisão Integrativa da Literatura Científica. Temas em Psicologia, v. 26, n. 3, p. 1527-1541, 2018. Disponível em: http://pepsic.bvsalud.org/scielo.php?script=sci_abstract\&pid=S1413$389 \times 2018000300014 \&$ Ing =pt\&nrm=iso\&tIng=pt. Acesso em: 20 set. 2020

OLIVEIRA, Givaldo Moisés. Comecei a sonhar com homens: a "saída do armário" vivenciada por homossexuais masculinos em suas interações familiares. (Dissertação de Mestrado). Universidade Estadual do Oeste do Paraná, Cascavel, PR, Brasil, 2019.

PERUCCHI, Juliana; BRANDÃO, Brune Coelho; VIEIRA, Hortênsia. Aspectos psicossociais da homofobia intrafamiliar e saúde de jovens lésbicas e gays. Estudos de Psicologia, v.19, n. 1, p. 67-76, 2014. Disponível em: https://www.scielo.br/scielo.php?script=sci_abstract\&pid=S1413294X2014000100009\&lng=en\&nrm=iso\&tlng=pt. Acesso em: 23 set. 2020.

PRADOS, Nathália Carneiro da Cunha; BRANDÃO, Brune Coelho; PERUCCHI, Juliana. Por onde circulam os corpos invisíveis? Intersecções entre população em situação de rua e gêneros dissidentes no acesso institucional urbano.

REBEH - Revista Brasileira de Estudos da Homocultura, v. 2, n. 01, p. 141-170, 2018. Disponível em: 
https://periodicoscientificos.ufmt.br/ojs/index.php/rebeh/article/view/9936. Disponível em: 12 set. 2020.

RAMOS, Douglas Oliveira. Famílias e homossexualidade: a experiência no centro de cidadania LGBT da capital. [SYN]THESIS, v. 9, n. 1, p. 63-73, 2016. Disponível em: https://www.e-

publicacoes.uerj.br/index.php/synthesis/article/view/42320. Acesso em: 12 set. 2020.

SANTOS, Manoel Antônio dos.; BROCHADO JUNIOR, José Urbano; MOSCHETA, Murilo dos Santos. Grupo de pais de jovens homossexuais. SMAD, Rev.

Eletrônica Saúde Mental Álcool Drogas, v. 3, n. 2, 2007. Disponível em: http://pepsic.bvsalud.org/scielo.php?script=sci_arttext\&pid=S180669762007000200002. Acesso em: 24 ago. 2020.

SANTOS, Maycon Regis Nogueira dos; GODOY, Emerson André de. Família e escola: a construção da homofobia no Brasil. Perspectivas em diálogo, v. 6, n. 11, 2019. Disponível em:

https://periodicos.ufms.br/index.php/persdia/article/view/7527\# : : text=Quan to $\% 20 \%$ C3\%A0\%20escola\%2C\%20esse\%20ambiente,indiv\%C3\%ADduos\%20 pertencentes\%20\%C3\%A0\%20comunidade\%20LGBT. Acesso em: 22 ago.

2020.

SANTOS, Silvana Mara Morais dos. O pensamento de esquerda e os limites da luta pela liberdade de orientação sexual. Presença Ética: Revista Anual do Grupo de Estudos e pesquisa sobre Ética (GEPE), n. 3, 2002.

SCHULMAN, Sarah. Homofobia familiar: uma experiência em busca de reconhecimento. Bagoas - Estudos gays: gênero e sexualidade, v. 4, n. 5, p. 68-78, 2010. Disponível em:

https://periodicos.ufrn.br/bagoas/article/view/2312. Acesso em: 19 set. 2020.

SEDGWICK, Eve Kosofsky. A epistemologia do armário. Cadernos pagu, v.

28, p. 19-54, 2007. Disponível em: https://www.scielo.br/pdf/cpa/n28/03.pdf. Acesso em: 25 out. 2020.

SILVA, Sergio Gomes da; FRANÇA, Alexandre Nabor. Vidas Precárias: a Performatividade na Constituição das Violências Fóbicas em Gêneros e Sexualidades. Psicologia: Ciência e Profissão, v. 39, p. 146-160, 2019.

Disponível em:

https://www.scielo.br/scielo.php?script=sci_arttext\&pid=S1414-

98932019000700309. Acesso em: 16 set. 2020.

SOLIVA, Thiago Barcelos; SILVA JUNIOR, João Batista. Entre revelar e esconder: pais e filhos em face da descoberta da homossexualidade. Sexualidad, Salud y Sociedad (Rio de Janeiro), n. 17, 
p.124-148, 2014. Disponível em: https://www.scielo.br/scielo.php?pid=S198464872014000200124\&script=sci_arttext. Acesso em: 09 set. 2020.

SOUZA, Marcela Tavares de; SILVA, Michelly Dias da; CARVALHO, Rachel de. Revisão integrativa: o que é e como fazer. Einstein (São Paulo), v. 8, n. 1, p. 102-106, 2010. Disponível em:

http://www.scielo.br/scielo.php?script=sci_arttext\&pid=S1679-

45082010000100102\&lng=en\&nrm=iso>. Acesso em: $21 \mathrm{dez} .2020$.

TOKUDA, André Masao Peres; PERES, Wiliam Siqueira; ANDRÊO, Caio. Família, gênero e emancipação psicossocial. Psicologia: Ciência e Profissão, v. 36, n. 4, p. 921-931, 2016. Disponível em:

https://www.scielo.br/scielo.php?pid=S1414-

98932016000400921\&script=sci_abstract\&tIng=pt. Acesso em: 09 set. 2020.

TOLEDO, Lívia Gonsalves.; TEIXEIRA-FILHO, Fernando Silva. Homofobia familiar: abrindo o armário entre quatro paredes. Arquivos Brasileiros de Psicologia, v. 65, n. 3, p. 376-391, 2013. Disponível em: http://pepsic.bvsalud.org/scielo.php?script=sci_artteext\&pid=S180952672013000300005. Acesso em: 17 set. 2020.

XAVIER, E. Declínio do patriarcado: a família no imaginário feminino. Rio de Janeiro: Record, 1988.

WARNER, M. Fear of a queer planet. Minneapolis: University of Minnesota, 1993.

Recebido em: 26 de fevereiro de 2021. Aceito em: 02 de abril de 2021. Publicado em: 30 de junho de 2021. 